\title{
Quality of life after esophageal resection
}

This article was published in the following Dove Press journal: Patient Related Outcome Measures

\section{Wendy Jo Svetanoff',2 \\ Rose McGahan ${ }^{2}$ \\ Saurabh Singhal ${ }^{3}$ \\ Carrie Bertellotti ${ }^{2}$ \\ Sumeet K Mittal ${ }^{2,3}$}

'Department of Pediatric Surgery, Boston Children's Hospital, Boston, MA, USA; 'Department of Surgery, Creighton University School of Medicine, Omaha, NE, USA; ${ }^{3}$ Norton Thoracic Institute, St. Joseph's Hospital and Medical Center, Phoenix, AZ, USA
Correspondence: Sumeet K Mittal Norton Thoracic Institute, St. Joseph's Hospital and Medical Center, 500 W Thomas Road, Suite 500, Phoenix, AZ 850 I 3, USA

Tel + I 6024064000

Fax + I 6024066498

Email Sumeet.Mittal@DignityHealth.org
Introduction: Esophageal resection is the primary treatment for malignant esophageal disease and the last resort for benign end-stage esophageal disease. There is a paucity of research comparing the long-term quality of life (QoL) following surgery among these two populations. The aim of this study was to examine the patient reported QoL after esophageal resection using questionnaires focusing on general well-being and esophageal-specific symptoms.

Methods: A prospectively maintained database of post-operatively administered European Organization for Research and Treatment of Cancer Quality of Life Questionnaire C30 (EORTC QLQ-C30) with supplemental esophageal cancer-specific questionnaires (OES-18) was queried after institutional review board approval through Creighton University School of Medicine. Inclusions were made if patients received an esophageal resection for benign or malignant esophageal disease. Emergency procedures, delayed reconstructions, and stage IV disease were excluded. Student's $t$-test was used for domains of function, symptoms, QoL, and esophagealspecific complaints to compare the groups with each other and with the general population.

Results: A total of 39 out of 248 patients with malignant disease and 24 out of 46 with benign disease completed the questionnaire. A mean post-operative follow-up of 53 months with a response rate of $40 \%$ was obtained. There was no difference in physical $(p=0.81)$, role $(p=0.37)$, conditional $(p=0.73)$, emotional $(p=0.06)$, or social functions $(p=0.42)$ between the general population and the esophageal resection groups. There was also no significant difference in generalized pain ( $p=0.86)$, nausea/vomiting $(p=0.27)$, fatigue $(p=0.86)$, swallowing $(p=0.35)$, or esophageal pain $(p=0.12)$. The malignant cohort had better outcomes than the benign cohort with respect to eating ( $p=0.04)$, indigestion $(p=0.04)$, and QoL $(p=<0.01)$.

Discussion: The underlying disease between these cohorts is drastically different, but postoperative functional status, generalized symptoms, swallowing ability, and esophageal pain were similar. There was no difference in functional status between the general population and the esophageal resection cohorts. Patients with malignant disease reported less problems with eating and a better QoL than their benign counterparts.

Keywords: quality of life, esophageal resection, esophageal cancer, esophagectomy, end-stage esophageal disease

\section{Introduction}

The number of esophageal resections being performed worldwide has been on the rise in recent years, both as the primary treatment for malignant disease as well as a last resort for benign end-stage esophageal disease (ESED). When evaluating patients with benign esophageal disease, a subset of patients have such deteriorated esophageal function that they can be best described as having ESED. This has most commonly included advanced stages of achalasia. Additionally, increased surgical interventions, 
the use of prosthetics at the hiatus, and the increased patient longevity have increased the pool of patients in this category. Esophageal resection remains the only viable option for these patients.

On a similar front, the incidence of esophageal cancer (EC) has steadily risen over the past 25 years, particularly in the western world with resectable esophageal adenocarcinoma. Historically, esophageal resection had been associated with prohibitive mortality. However, tri-modality treatment, including esophageal resection with adjuvant chemoradiotherapy, has become commonplace with a 3-year survival reaching up to $50 \%{ }^{1,2}$ Orringer and Sloan were the first to report a series of transhiatal esophagectomies with less than $10 \%$ peri-operative mortality. ${ }^{3}$ Subsequently, with improvements in surgical technique and post-operative critical care management, the peri-operative mortality has decreased to low single digits at high volume centers.

With improved survival, the focus has shifted from perioperative morbidity and mortality to long-term quality of life (QoL) for these patients. The aim of this study was to systematically examine the patient reported QoL after esophageal resection using questionnaires focusing on general well-being and esophageal-specific symptoms.

\section{Methods}

\section{Study design}

All patients undergoing esophageal surgery at Creighton University Medical Center were entered in a prospectively maintained database. The European Organization for Research and Treatment of Cancer Quality of Life Questionnaire C30 (EORTC QLQ-30) and supplemental esophageal cancer-specific questionnaires (EORTC QLQ-OES-18) were administered during follow-up in clinic or mailed to the patient as part of routine long-term post-operative management. The questionnaires and consent forms were completed and returned to the surgical department to be added to the database.

\section{Participants}

After institutional review board approval from Creighton University School of Medicine, the database was queried to identify patients who underwent esophageal resection from April 2004 to February 2015. Data pertaining to the indication of surgery (malignant and benign), demographics, procedure performed, and conduit used was extracted into a Microsoft Excel spreadsheet (Microsoft Corporation, Redmond, WA, USA). All types of esophageal resections (ie, Ivor Lewis, McKeown, and transhiatal with either gastric pull-up or jeju- nal/colonic interposition) and approaches (open, minimally invasive, or hybrid) were included. Patients who underwent esophageal resection with delayed reconstruction, stage IV disease, emergency procedures, or those who died during follow-up were excluded.

\section{Health-related quality of life (HRQoL) measurements}

The HRQoL assessment was done using the cancer-specific EORTC QLQ-C30 and the adjuvant esophageal diseasespecific EORTC QLQ-OES 18 module. The EORTC QLQ$\mathrm{C} 30$ is a systematic 30 -item questionnaire established to assess the QoL of all cancer patients. ${ }^{4}$ Permission to use the questionnaires was obtained from the EORTC Quality of Life Department, with subsequent access to the specific questionnaires through the website: http://groups.eortc.be/ qol/eortc-qlq-c30. It is comprised of five functional scales, three symptom scales, and one global QoL scale. The five functional scales measured physical function, role function, emotional function, cognitive function, and social function. For symptom scales, patients were questioned on pain, fatigue, nausea and vomiting, dyspnea, insomnia, appetite loss, constipation, diarrhea, or financial difficulties. Diseasespecific modules (like the EORTC QLQ-OES18 esophageal module) were also available for specific cancer subtypes. It was a ten-scale assessment with questions regarding the following esophageal functional and symptomatic scales: swallowing, eating, reflux, pain, saliva, choking, dry mouth, taste, cough, and talking. Both of these scales had response options in four categories: "not at all", "a little", "quite a bit", and "very much". The exceptions to these categorical responses were the two questions assessing the global QoL; responses were gauged on a seven-categorical range with the lowest being "very poor" to the highest being "excellent". These questionnaires are available from the EORTC website. ${ }^{5}$ These surveys have been standardized with values available for the general population (without cancer) and for patients with specific cancer diagnoses who have not undergone surgery. ${ }^{4,6,7}$ The data for the general population were extracted from these surveys for controlled comparison. ${ }^{8-11}$

\section{Statistical analysis}

Responses from the questionnaires were represented as mean and SDs. Responses were segregated into either malignant or benign disease, and a linear regression scale was applied to the mean values to transform scores into a scale ranging from 0 to 100. The multiple regression model was based on the dependent variable of disease state (benign or malignant) 
and the independent variables of age, gender, comorbidities, approach, conduit, and anastomosis. To counter the possibility of type I error, independent variables were measured twice by two authors (RM and WJS). It was assumed that errors of measurement on different occasions were uncorrelated based on the work by Campbell and Fiske, who looked at methodology in linear regression models. ${ }^{12}$ This method of linear regression also was in accordance with the EORTC scoring manual. ${ }^{4}$ Responses that were not documented were handled according to the scoring manual's recommendations. A higher score for any functional or QoL scale indicated an overall healthier level of functional capabilities. Alternatively, higher linear regression scores on the symptom scales indicated increased symptomatic complaints for daily QoL. The Student's $t$-test was used to determine any significant difference between the control group of patients compared to the entire population who received esophageal resection. Additionally, a subset analysis to check for the homogeneity of the data while using a parametric test was done by a Tukey post hoc test for the functional scales of appetite loss, sleep function, constipation, diarrhea, and financial difficulties as the assessment only contained one question for these categories. Significance was set at $p<0.05$.

\section{Results \\ Patient demographics}

A total of 294 esophageal resections were performed during the study period, 248 (84\%) for malignant disease, and $46(16 \%)$ for benign indications. One hundred-twenty-six patients died before the completion of the study (116 in the malignant cohort, ten in the benign cohort) making 168 patients available to complete the questionnaires. Sixty-three patients (43 males) completed the HRQoL questionnaires, including 39 patients with EC and 24 with ESED. One patient in the malignant cohort and three patients in the benign cohort were excluded as per the exclusion criteria. The consort diagram of patient recruitment is shown in Figure 1. The age for the entire cohort ranged from 44 to 81 years with a mean age of 61.97 years for the malignant group and 63.81 years for the benign group. The mean time since surgery was 5.2 years for the entire cohort and was significantly higher for the benign group compared to those who underwent surgery for malignant indications $(67.7 \pm 37.9$ months vs. $41.7 \pm 31.1$ months, respectively). The demographic characteristics for all three groups (entire esophageal resection population, benign esophageal resection cohort, and malignant esophageal resection cohort) are shown in Table 1 . There was a significantly

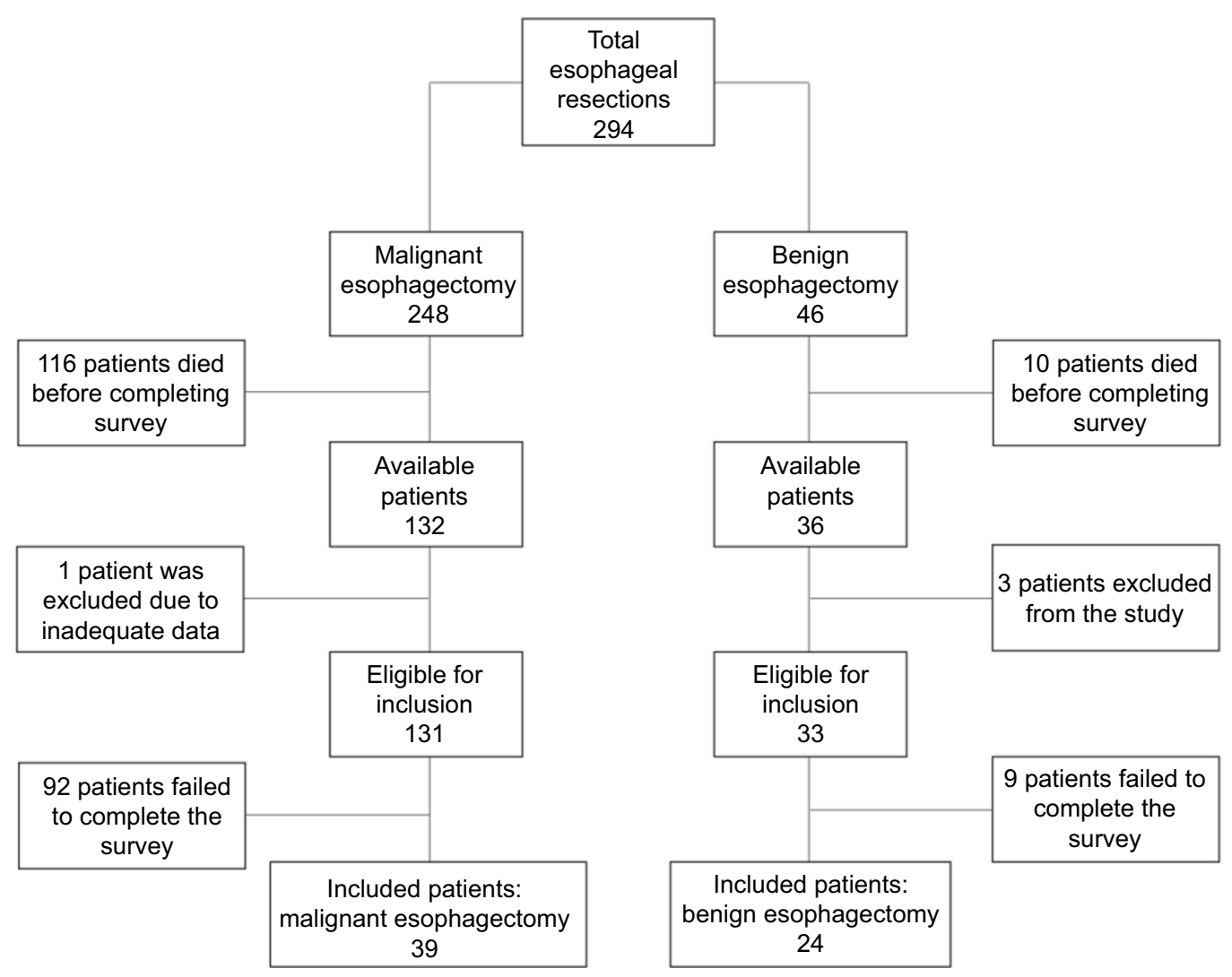

Figure I Flow diagram depicting inclusion of patients based on questionnaire response among all patients. 
Table I Demographic characteristics of patients undergoing esophageal resection either for benign or malignant disease

\begin{tabular}{|c|c|c|c|}
\hline Characteristics & Total included patients, n (\%) & Malignant disease, $\mathbf{n}(\%)$ & Benign disease, $\mathbf{n}(\%)$ \\
\hline Patients (N) & 63 & 39 & 24 \\
\hline \multicolumn{4}{|l|}{ Gender } \\
\hline Male & $43(68.25)$ & $33(84.62)$ & $10(40.74)$ \\
\hline Female & $20(31.75)$ & $6(15.38)$ & $14(59.26)$ \\
\hline \multicolumn{4}{|l|}{ Age (years) } \\
\hline$<40$ & 0 & 0 & 0 \\
\hline $40-49$ & I (I.59) & 0 & I (4.17) \\
\hline $50-59$ & $23(36.5 I)$ & $15(38.46)$ & $8(33.3)$ \\
\hline $60-69$ & $22(34.92)$ & $16(41.03)$ & $6(25.00)$ \\
\hline $70-79$ & $16(25.40)$ & $7(17.95)$ & $9(37.50)$ \\
\hline $80+$ & I (I.59) & I (2.56) & 0 \\
\hline \multicolumn{4}{|l|}{ Comorbidities } \\
\hline Yes & $53(84.13)$ & $35(89.74)$ & $18(75.00)$ \\
\hline No & $10(15.87)$ & $4(10.26)$ & $6(25.00)$ \\
\hline \multicolumn{4}{|l|}{ Dysplasia } \\
\hline HGD/EAC & $N / A$ & $36(92.30)$ & $\mathrm{N} / \mathrm{A}$ \\
\hline SCC & $N / A$ & $3(7.70)$ & $\mathrm{N} / \mathrm{A}$ \\
\hline \multicolumn{4}{|l|}{ Tumor location } \\
\hline Upper/Middle esophagus & $N / A$ & $\mathrm{I}(2.56)$ & $\mathrm{N} / \mathrm{A}$ \\
\hline Lower esophagus & N/A & $33(84.62)$ & $\mathrm{N} / \mathrm{A}$ \\
\hline Proximal stomach & N/A & $5(12.82)$ & $\mathrm{N} / \mathrm{A}$ \\
\hline \multicolumn{4}{|l|}{ Grade } \\
\hline $0-1$ & $N / A$ & $10(25.64)$ & $\mathrm{N} / \mathrm{A}$ \\
\hline II & $N / A$ & $25(64.10)$ & $\mathrm{N} / \mathrm{A}$ \\
\hline III & $\mathrm{N} / \mathrm{A}$ & $4(10.26)$ & $\mathrm{N} / \mathrm{A}$ \\
\hline \multicolumn{4}{|l|}{ Dysfunction } \\
\hline Achalasia & $N / A$ & $N / A$ & $14(58.33)$ \\
\hline Diffuse esophageal spasm & $N / A$ & $\mathrm{~N} / \mathrm{A}$ & $2(8.33)$ \\
\hline Stricture & $N / A$ & $\mathrm{~N} / \mathrm{A}$ & $3(12.50)$ \\
\hline Mesh erosion & $\mathrm{N} / \mathrm{A}$ & $N / A$ & I (4.17) \\
\hline Gastroesophageal reflux disease & $\mathrm{N} / \mathrm{A}$ & $\mathrm{N} / \mathrm{A}$ & I (4.17) \\
\hline Diverticulum & $\mathrm{N} / \mathrm{A}$ & N/A & I (4.17) \\
\hline \multicolumn{4}{|l|}{ Approach } \\
\hline Minimally invasive & $30(47.62)$ & $25(64.10)$ & $5(20.83)$ \\
\hline Open & $31(49.21)$ & $13(33.33)$ & $18(75)$ \\
\hline Hybrid & $2(3.17)$ & $\mathrm{I}(2.56)$ & I (4.17) \\
\hline \multicolumn{4}{|l|}{ Conduit } \\
\hline Stomach & $54(85.7 \mathrm{I})$ & $38(97.44)$ & $16(66.67)$ \\
\hline Jejunum & $4(6.35)$ & I $(2.56)$ & $3(12.50)$ \\
\hline Colon & $5(7.94)$ & N/A & $5(20.83)$ \\
\hline \multicolumn{4}{|l|}{ Anastomosis } \\
\hline Stapled & $34(53.97)$ & $24(61.54)$ & $10(41.67)$ \\
\hline Hand-sewn & $29(46.03)$ & $15(38.46)$ & $14(58.33)$ \\
\hline
\end{tabular}

Abbreviations: HGD/EAC, high-grade dysplasia/early adenocarcinoma; SCC, squamous cell carcinoma; N/A, not applicable.

higher number of males $(84.6 \%)$ in the malignant group compared to the benign group (40.7\%). Most patients $(84.1 \%)$ had comorbidities that included, but were not limited to, diabetes mellitus, hypertension, and chronic obstructive pulmonary disease. The primary indications for esophageal resection in patients with malignant disease were high-grade dysplasia and adenocarcinoma (92.3\%); a majority of these operations were performed through minimally invasive surgical techniques $(64.1 \%)$ with a gastric conduit $(97.4 \%)$ and a stapled anastomosis $(61.5 \%)$. The primary indication for performing an esophageal resection in the benign group was end-stage achalasia (58.3\%), with symptoms of dysphagia (79.1\%) and regurgitation (44.2\%) being most common. Another common indication was esophageal stricture (12.5\%). The majority of these operations were performed via an open approach (75\%) using a gastric conduit (66.7\%) and a hand-sewn anastomoses $(58.3 \%)$ (Table 1).

The patient demographics for the control group (general population) were obtained from the EORTC reference document. ${ }^{5}$ The normal population was comprised of roughly an equal 
Table 2 Linear regression analysis of our total esophageal resection cohort compared to general population: functional domains (all questions are answered in the context of the past week)

\begin{tabular}{|c|c|c|c|}
\hline Functional domain questions & $\begin{array}{l}\text { General } \\
\text { population } \\
\text { (LRS) }\end{array}$ & $\begin{array}{l}\text { Total patients with } \\
\text { esophageal resection } \\
\text { (LRS) }\end{array}$ & $p$-value \\
\hline Physical function & & & 0.24 \\
\hline Do you have any trouble doing strenuous activities? & 76.05 & 67.72 & \\
\hline Trouble with long walks? & 84.28 & 66.22 & \\
\hline Trouble taking short walk outside of house? & 93.84 & 87.98 & \\
\hline Do you need to stay in bed or a chair during the day? & 95.41 & 82.79 & \\
\hline Do you need help with eating? Dressing? Washing yourself or using the toilet? & 98.74 & 97.37 & \\
\hline Role function & & & 0.40 \\
\hline Were you limited in doing your work? & 84.09 & 84.31 & \\
\hline Were you limited in pursuing your hobbies/leisure activities? & 84.77 & 82.70 & \\
\hline Generalized pain & & & 0.97 \\
\hline Have you had pain in the past week? & 22.98 & 29.42 & \\
\hline Did pain interfere with your daily activities? & 19.00 & 19.11 & \\
\hline Nausea and vomiting & & & 0.09 \\
\hline Have you felt nauseated? & 5.62 & 14.02 & \\
\hline Have you vomited? & 1.90 & 10.14 & \\
\hline Fatigue & & & 0.13 \\
\hline Did you need to rest? & 24.78 & 32.30 & \\
\hline Were you tired? & 28.84 & 38.85 & \\
\hline Emotional function & & & 0.70 \\
\hline Did you feel tense? & 77.17 & 75.31 & \\
\hline Did you worry? & 72.18 & 67.15 & \\
\hline Did you feel irritable? & 75.59 & 79.17 & \\
\hline Did you feel depressed? & 79.76 & 77.99 & \\
\hline Social function & & & 0.09 \\
\hline Has your physical condition or medical treatment interfered with your family life? & 87.92 & 79.55 & \\
\hline Has your physical condition or medical treatment interfered with your social activities? & 86.83 & 72.43 & \\
\hline Generalized quality of life & & & 0.65 \\
\hline How would you rate your overall health? & 70.80 & 71.10 & \\
\hline How would you rate your overall quality of life? & 71.85 & 70.98 & \\
\hline Conditional function & & & 0.94 \\
\hline Have you had difficulty remembering things this past week? & 88.77 & 78.72 & \\
\hline Have you had difficulty with your daily activities? & 83.33 & 87.82 & \\
\hline
\end{tabular}

Abbreviation: LRS, linear regression analysis.

number of male and female participants (51.9\% vs. $48.1 \%)$; approximately one third of the participants were under the age of 40 , and $56 \%$ of patients were between the ages of 40 and 70 .

\section{HRQoL: functional status}

When comparing the responses of all patients who received esophageal resections vs. the general population, there appeared to be no statistical difference in physical function, emotional function, social function, conditional function, or role function $(p>0.05)$ (Table 2$)$.

\section{HRQoL: symptom status}

There was no difference in generalized pain, nausea, or fatigue between patients undergoing an esophageal resection and the general population $(p>0.05)$ (Table 2$)$. There was no symptomatic difference between patients who had a resection for either malignant or benign disease.

\section{Global QoL status}

The global QoL status did not differ between the general population and patients who underwent an esophageal resection $(p>0.05)$. When asked about overall health during the past week, the linear regression score for global QoL was less in the general population (70.8) than the patients within our subset of analysis (71.10). However, when asked to rate their overall QoL, the general population scored higher (71.85) than those who received an esophageal resection (70.98). Patients with end-stage benign disease reported a significantly lower overall health (67.20) and overall QoL (66.13) than those with malignant disease (75.00 and 75.83, respectively) (Table 3). 
Table 3 Linear regression analysis of the EORTC QLQ-C30 and specific esophageal symptoms of patients undergoing esophageal resection for benign and malignant disease

\begin{tabular}{|c|c|c|c|}
\hline EORTC QLQ-C30 Domains & $\begin{array}{l}\text { End stage benign } \\
\text { disease (LRS) }\end{array}$ & $\begin{array}{l}\text { Malignant } \\
\text { disease (LRS) }\end{array}$ & $p$-value \\
\hline Physical function & & & 0.81 \\
\hline Do you have any trouble doing strenuous activities? & 72.22 & 75.21 & \\
\hline Trouble with long walks? & 68.89 & 70.94 & \\
\hline Trouble taking short walk outside of house? & 89.25 & 94.17 & \\
\hline Do you need to stay in bed or a chair during the day? & 89.25 & 89.17 & \\
\hline Do you need help with eating? Dressing? Washing yourself or using the toilet? & 100.00 & 100.00 & \\
\hline Role function & & & 0.37 \\
\hline Were you limited in doing your work? & 84.44 & 84.17 & \\
\hline Were you limited in pursuing your hobbies/leisure activities? & 79.57 & 85.83 & \\
\hline Generalized pain & & & 0.86 \\
\hline Have you had pain in the past week? & 27.96 & 25.83 & \\
\hline Did pain interfere with your daily activities? & 16.13 & 15.00 & \\
\hline Nausea and vomiting & & & 0.27 \\
\hline Have you felt nauseated? & 18.89 & 9.17 & \\
\hline Have you vomited? & 11.11 & 9.17 & \\
\hline Fatigue & & & 0.86 \\
\hline Did you need to rest? & 29.03 & 28.33 & \\
\hline Were you tired? & 40.86 & 35.00 & \\
\hline Emotional function & & & 0.06 \\
\hline Did you feel tense? & 79.57 & 71.04 & \\
\hline Did you worry? & 74.20 & 60.10 & \\
\hline Did you feel irritable? & 80.65 & 77.70 & \\
\hline Did you feel depressed? & 82.80 & 73.18 & \\
\hline Social function & & & 0.43 \\
\hline Has your physical condition or medical treatment interfered with your family life? & 79.57 & 79.53 & \\
\hline Has your physical condition or medical treatment interfered with your social activities? & 73.12 & 71.74 & \\
\hline Generalized quality of life & & & 0.01 \\
\hline How would you rate your overall health? & 67.20 & 75.00 & \\
\hline How would you rate your overall quality of life? & 66.13 & 75.83 & \\
\hline Conditional function & & & 0.73 \\
\hline Have you had difficulty remembering things this past week? & 91.40 & 84.24 & \\
\hline Have you had difficulty with your daily activities? & 75.27 & 82.18 & \\
\hline \multicolumn{4}{|l|}{ Esophageal-specific domains } \\
\hline Swallowing & & & 0.35 \\
\hline During the past week could you eat solid food? & 12.90 & II.II & \\
\hline Could you eat liquefied or soft food? This past week & 5.38 & 12.04 & \\
\hline Could you drink liquids this past week? & 3.23 & 8.33 & \\
\hline Eating & & & 0.04 \\
\hline Have you had trouble enjoying your meals? & 48.93 & 20.37 & \\
\hline Have you felt full up too quickly? & 38.70 & 37.04 & \\
\hline Have you had trouble with eating? & 56.20 & 19.44 & \\
\hline Have you had trouble with eating in front of other people? & 28.07 & 8.33 & \\
\hline Indigestion & & & 0.04 \\
\hline Have you had acid indigestion or heartburn? & 33.33 & 18.52 & \\
\hline Have you had trouble with acid or bile coming into your mouth? & 29.032 & 21.292 & \\
\hline Pain & & & 0.12 \\
\hline Have you had pain in your chest? & 28.49 & 5.56 & \\
\hline
\end{tabular}

Notes: Only the generalized quality of life showed significant difference, with those in the malignant group claiming a better overall quality of life. The EORTC QLQ-C30 specimen was adapted and used with permission from the European Organization for Research and Treatment of Cancer; EORTC Quality of Life Department. EORTC QLQ-C30 (version 3). Available from: http://groups.eortc.be/qoll. @ Copyright 1995 EORTC Quality of Life Group. All rights reserved. Version 3.0.35 Please contact the EORTC Quality of Life Department for any further use of the questionnaire.

Abbreviations: EORTC QLQ-C30, European Organization for Research and Treatment of Cancer Quality of Life Questionnaire C30; LRS, linear regression analysis.

Esophageal-specific function and symptoms

On comparing the benign cohort with the malignant cohort following esophageal resection, no statistical difference was found in any of the functional domains: physical, role, emotional, social, or cognitive domains ( $p>0.05)$ (Table 3$)$. In the symptomatic domains, there was no statistical difference in generalized pain, nausea or vomiting, or fatigue $(p>0.05)$. 
Patients with ESED had significantly more symptoms in the domains of difficulty in eating $(p=0.04)$ and indigestion $(p=0.04)$ (Table 3).

\section{Discussion}

Esophageal resection is the definitive treatment for patients with end-stage benign esophageal disease as well as those with EC. The overall survival of patients depends on multiple factors including, but not limited to, stage, oncologic margins, operative mortality, and adjuvant treatment. As the technique of surgery and peri-operative care have improved, the focus has shifted toward the QoL of these patients. There is a paucity of data using the EORTC questionnaire for postoperative QoL assessment in patients undergoing esophageal resection for benign disease. Most of the literature on QoL research has focused on outcomes after surgery for EC, but few have looked at outcomes after esophageal resection for benign disease. However, multiple studies have noted the feasibility of using the EORTC questionnaire to assess QoL after resection for benign disease in other areas. ${ }^{13-16}$ As the questionnaires focus on QoL from a functional standpoint, these assessments can be utilized for all patients who undergo the same surgical procedure, independent of the indication. As benign ESED has continued to rise, these quality measures will be important to help counsel future patients about their treatment options. We aimed to look at the QoL of these patients using the EORTC QLQ-C30 questionnaire in comparison with general population and patients with EC before esophageal resection.

When comparing the functional status of patients who received an esophageal resection to the general population, there was no difference found in the domains of physical, role, emotional, social, or cognitive function. However, other studies have demonstrated a significant reduction in global health status 1 year post-esophageal resection. ${ }^{17,18}$ A previous study found that all functional scales, aside from emotional function, were significantly worse when compared to the healthy reference population. ${ }^{19}$ There was not a statistical difference in the overall QoL when comparing functional status following an esophageal resection to a control consisting of patients with an early Barrett's diagnosis. ${ }^{20}$ Another study suggested that patient HRQoL reaches a nadir 2 months post-operatively, with overall QoL continuing to improve significantly 1 year post-esophageal resection. ${ }^{21}$ These findings were supported by another study in 2015, which found that the HRQoL drastically improved for patients undergoing esophageal resection at 6 months follow-up. ${ }^{22}$ A possible cause for the lack of difference in functional status between our patients who received an esophageal resection vs. the general population may lie in the length of our post-operative follow-up. Further, there was no statistical difference in any functional domain when comparing patients with malignant disease to those with end-stage benign disease.

While the indications for esophageal resection have been well-defined, the morbidity and mortality associated with the surgery have been more concerning. Depending on the study, morbidity and mortality rates have varied, averaging between $25 \%-50 \%$ and $6 \%-23 \%$ respectively. The biggest immediate complications have included anastomotic leak, arrhythmias, pulmonary complications, chylothorax, need for reoperation, and anastomotic stricture. ${ }^{21}$ These complications have been even more prominent in patients undergoing esophageal resection for benign indications. Reflux has continued to remain a high post-operative complication following esophageal resection. There appeared to be no statistical difference for nausea and vomiting, fatigue, or generalized pain between the various groups in our patient cohort, however, there may be a possible bias in the symptom scores reported by the patients. Patients who have completely recovered from their surgical procedure with no acute complications are more likely to report a lower symptom score.

In addition, the incidence of gastroesophageal reflux disease has continued to rise within the general population. ${ }^{22}$ Evidence may suggest that early intervention of gastroesophageal disease, like the LINX sphincter augmentation device, may prove beneficial to diminish progression to end-stage disease. $^{23}$ The causative factors for progression of benign esophageal disease to end-stage disease have been poorly understood. Factors that may contribute to a rapid progression to end-stage disease, and thus requiring surgical intervention, have included previous fundoplication, initial esophageal intervention at age 18 or older, or the presence of an acquired esophageal disease. ${ }^{22}$ The patients who have undergone surgical resection for benign disease often have undergone repeated endoscopic procedures and additional esophageal interventions prior to definitive end-stage surgical treatment. ${ }^{24}$ Reconstructing the esophagus by surgical intervention can be particularly difficult for patients who have already undergone extensive esophageal procedures. ${ }^{22}$ If disease progression does result in end-stage benign disease, there is no significant deviation in QoL post-esophageal resection compared to their normal counterparts, as suggested by our study.

When comparing the subset of patients who received an esophageal resection for benign esophageal disease to their malignant counterparts, patients with malignant disease reported an overall better QoL than those with end-stage 
benign disease. Additionally, patients who underwent an esophageal resection for benign disease reported statistically higher issues with eating and higher average scores for indigestion when compared to the malignant cohort. Several possibilities have accounted for these findings. The psychological impact of having survived cancer may reflect in higher reported QoL scores when compared with patients who underwent elective esophageal resection for end-stage benign disease. A sample of 26 people, all of whom received major upper gastrointestinal surgery, reported increased emotionally maladaptive responses like anxiety and depression following development of difficulty in eating. ${ }^{25}$ Higher symptomatic complaints within the domain of eating for patients with end-stage benign disease may account for the decreased QoL when compared to their malignant counterparts. Additionally, a psychological assessment of 51 patients with documented GERD found a higher frequency of psychologically distressed patients with GERD than their normal counterparts. ${ }^{26}$ The higher prevalence of psychological distress in patients suffering from benign esophageal disease may allude to the increased distress despite surgical intervention. ${ }^{27}$ Little is known regarding the functional status of patients with endstage benign disease post-esophagectomy; what our study and other studies have suggested is that patients with end-stage benign disease may have higher psychological concerns than their malignant counterparts. Further management of any psychological distress should be addressed to better understand the root cause of such concerns.

\section{Strengths and limitations}

Only a few studies have analyzed the overall QoL postresection for the curative treatment of EC. ${ }^{28,29}$ Multiple studies have solidified that the long-term QoL after esophagectomy is comparable to healthy reference cohorts. ${ }^{29-32}$ Zhang et al reported that postoperative QoL of patients who survived 21 months following Ivor Lewis Esophagectomy with no signs of recurrence reported higher mean scores for both general QoL and global health status. ${ }^{32}$ One of the strengths of our study was the long median follow-up time. We analyzed the post-operative QoL of patients who survived esophageal resection for both benign and malignant variants at an average of 4.3 years post-operatively and found no significant difference when compared to their healthy counterparts. Our study supported Zhang's study as our patients who underwent esophageal resection for cancer reported statistically higher global health status, while the general QoL scores were found to be higher in the general population. Despite this, no statistical difference was found in the general QoL $(p=0.65)$.
To the best of our knowledge, this is the only study that has contrasted the HRQoL within this subset of patients following esophageal resection. Additionally, one of the strengths of this study includes the largest cohort of patients undergoing esophageal resection for benign disease. While collectively all patients who underwent an esophageal resection had no statistical difference in generalized QoL when compared to the general population, we found that patients who underwent the procedure for malignant indications had overall higher QoL ratings than the patients with benign disease.

There were a number of limitations that were unavoidable when using the EORTC HRQoL survey. With using the EORTC HRQoL survey, we were limited to specific questions to evaluate the overall QoL. In addition, multiple studies have attempted to assess the effect of the type of anastomosis, type of conduit, and type of procedure, and their effect on overall QoL..$^{20,21,27,33}$ On average, more minimally invasive procedures were performed for malignant disease in our study, and more open procedures were performed on patients with end-stage benign disease. The characteristics of conduits and anastomoses type were also varied within our cohort of patients. In addition, the age range of our patients varied significantly. However, based on the findings by O'Grady et al, there appeared to be no correlation of age leading to increased post-operative complications if patients were selected appropriately. ${ }^{34}$ The small number of overall patients in the study was another limitation, as this was a single institution study; therefore, adjusting for certain variables, such as type of surgery and type of conduit, could not be analyzed separately without compromising the integrity of the statistical analysis.

\section{Conclusion}

There is still room to better our understanding of the impact of an esophageal resection on the QoL of our patients. Our findings indicated that there was no difference in the functional status or symptom management for patients after esophageal resection for both malignant and benign disease when compared to that of the general population. Patients contemplating this procedure should find comfort in these findings. Unfortunately, those undergoing an esophageal resection for benign disease did have poorer overall QoL than their malignant counterparts or the general population.

\section{Acknowledgments}

We would like to acknowledge the expertise of Paul Kang, MS, MPH, from the University of Arizona College of Public Health for his review of the statistical methods and rigor. 
This research was presented at the ISDE Conference in Singapore, September 2016 and at the ACS Clinical Congress in Washington DC, October 2016. The EORTC questionnaire was obtained after contact with the EORTC QOL Department, who authorized a specimen of the questionnaire to be published. Please contact the EORTC QOL Department for any further use of the questionnaire.

\section{Disclosure}

The authors report no conflicts of interest in this work.

\section{References}

1. Fujiwara Y, Yoshikawa R, Kamikonya N, et al. Trimodality therapy of esophagectomy plus neoadjuvant chemoradiotherapy improves the survival of clinical stage II/III esophageal squamous cell carcinoma patients. Oncol Rep. 2012;28(2):446-452.

2. Shao MS, Wong AT, Schwartz D, Weiner JP, Schreiber D. Definitive or preoperative chemoradiation therapy for esophageal cancer: patterns of care and survival outcomes. Ann Thorac Surg. 2016;101(6):2148-2154.

3. Orringer MB, Sloan H. Esophagectomy without thoracotomy. J Thorac Cardiovasc Surg. 1978;76(5):643-654.

4. Aaronson NK, Ahmedzai S, Bergman B, et al. The European Organization for Research and Treatment of Cancer QLQ-C30: a quality-of-life instrument for use in international clinical trials in oncology. $J$ Natl Cancer Inst. 1993;85(5):365-376.

5. European Organization for Research and Treatment of Cancer (EORTC). Questionnaires. Available from: http://groups.eortc.be/qol/. Accessed January 15, 2018.

6. Osoba D, Pater JL, Zee B. Effective anti-emetic therapy improves quality of life (QoL) after moderately emetogenic chemotherapy (MEC). Qual Life Res. 1995;4(5):467-468.

7. Kaasa S, Bjordal K, Aaronson N, Moum T, Wist E, Hagen S, Kvikstad A. The EORTC core quality of life questionnaire (QLQ-C30): validity and reliability when analyzed with patients treated with palliative radiotherapy. Eur J Cancer. 1995;31A(13-14):2260-2263.

8. Klee M, Groenvold M, Machin D. Quality of life of Danish women: population-based norms of the EORTC QLQ-C30. Qual Life Res. 1997;6(1):27-34.

9. Hjermstad MJ, Fayers PM, Bjordal K, Kaasa S. Health-related quality of life in the general Norwegian population assessed by the European Organization for Research and Treatment of Cancer Core Quality of Life Questionnaire: the QLQ=C30 (+ 3). J Clin Oncol. 1998;16(3):1188-1196.

10. Schwarz R, Hinz A. Reference data for the quality of life questionnaire EORTC QLQ-C30 in the general German population. Eur J Cancer 2001;37(11):1345-1351.

11. Holzner B, Kemmler G, Cella D, et al. Normative data for functional assessment of cancer therapy. Acta Oncol. 2004;43(2):153-160.

12. Campbell DT, Fiske DW. Convergent and discriminant validation by the multi-trait multi-method matrix. Psychol Bull. 1959;56(2):81-105.

13. Ciuman RR, Oels W, Jaussi R, Dost P. Outcome, general, and symptomspecific quality of life after various types of parotid resection. Laryngoscope. 2012;122(6):1254-1261.

14. Gunsoy, B, Vuralkan, E, Sonbay, ND, Simsek, G, Tokgoz, Akin I. Quality of life following surgical treatment of benign parotid disease. Indian J Otolarygol Head Neck Surg. 2013;65 (Suppl 1):105-111.

15. Epelboym I, Winner M, DiNorcia J, et al. Quality of life in patients after total pancreatectomy is comparable with quality of life in patients who undergo a partial pancreatic resection. J Surg Res. 2014;187(1):189-196.
16. Fong ZV, Alvino DM, Castillo CF, et al. Health-related quality of life and functional outcomes in 5-year survivors after pancreaticoduodenectomy. Ann Surg. 2017;266(4):685-692.

17. Donohoe CL, McGillycuddy E, Reynolds JV. Long-term health-related quality of life for disease-free esophageal cancer patients. World J Surg. 2011;35(8):1853-1860.

18. Gutschow CA, Hölscher AH, Leers J, et al. Health-related quality of life after Ivor Lewis esophagectomy. Langenbecks Arch Surg. 2013;398(2): 231-237.

19. Jacobs M, Macefield RC, Blazeby JM, et al. Systematic review reveals limitations of studies evaluating health-related quality of life after potentially curative treatment for esophageal cancer. Qual Life Res. 2013;22(7):1787-1803.

20. Zapletal C, Heesen C, Origer J, Pauthner M, Pech O, Ell Ch, Lorenz D. Quality of life after surgical treatment of early Barrett's cancer: a prospective comparison of the Ivor-Lewis resection versus the modified Merendino resection. World J Surg. 2014;38(6):1444-1452.

21. Malmström M, Klefsgard R, Ivarsson B, Roman M, Johansson J. Quality of life measurements as an indicator for timing of support after oesophagectomy for cancer: a prospective study. BMC Health Serv Res. 2015;15:96.

22. Huang Q, Zhong J, Yang T, et al. Impacts of anastomotic complications on the health-related quality of life after esophagectomy. J Surg Oncol. 2015;111(4):365-370

23. Shen KR, Harrison-Phipps KM, Cassivi SD, et al. Esophagectomy after anti-reflux surgery. J Thorac Cardiovasc Surg. 2010;139(4):969-975.

24. Buntain WL, Payne WS, Lynn HB. Esophageal reconstruction for benign disease: a long-term appraisal. Am Surg. 1980;46(2):67-79.

25. Bailey SH, Bull DA, Harpole DH, et al. Outcomes after esophagectomy: a ten-year prospective cohort. Ann Thorac Surg. 2003;75(1):217-222; discussion 222.

26. Carey S, Laws R, Ferrie S, Young J, Allman-Farinelli M. Struggling with food and eating--life after major upper gastrointestinal surgery. Support Care Cancer. 2013;21(10):2749-2757.

27. Baker LH, Lieberman D, Oehlke M. Psychological distress in patients with gastroesophageal reflux disease. Am J Gastroenterol. 1995;90(10):1797-1803.

28. de Boer AG, van Lanschot JJB, van Sandick JW, et al. Quality of life after transhiatal compared with extended transthoracic resection for adenocarcinoma of the esophagus. J Clin Oncol. 2004;22(20):4202-4208.

29. Däster S, Soysal SD, Stoll L, Peterli R, von Flüe M, Ackermann C. Long-term quality of life after Ivor Lewis esophagectomy for esophageal cancer. World J Surg. 2014;38(9):2345-2351.

30. Courrech Staal EFW, van Sandick JW, van Tinteren H, Cats A, Aaronson NK. Health-related quality of life in long-term esophageal cancer survivors after potentially curative treatment. JThorac Cardiovasc Surg. 2010;140(4):777-783.

31. Gockel I, Gönner U, Domeyer M, Lang H, Junginger T. Long-term survivors of esophageal cancer: disease-specific quality of life, general health and complications. J Surg Oncol. 2010;102(5):516-522.

32. Zhang M, Li Q, Tie HT, Jiang YJ, Wu QC. Methods of reconstruction after esophagectomy on long-term health-related quality of life: a prospective, randomized study of 5-year follow-up. Med Oncol. 2015;32(4):122.

33. Liu QX, Qiu Y, Deng XF, Min JX, Dai JG. Comparison of outcomes following end-to-end hand-sewn and mechanical oesophagogastric anastomosis after oesophagectomy for carcinoma: a prospective randomized controlled trial. Eur J Cardiothorac Surg. 2015;47(3):e118-123.

34. O'Grady G, Hameed AM, Pang TC, Johnston E, Lam VT, Richardson AJ, Hollands MJ. Patient selection for oesophagectomy: impact of age and comorbidities on outcome. World J Surg. 2015;39(8):1994-1999.

35. European Organization for Research and Treatment of Cancer; EORTC Quality of Life Department. EORTC QLQ-C-30 (version 3). Available from: http://groups.eortc.be/qol/. Accessed February 22, 2018. 


\section{Publish your work in this journal}

Patient Related Outcome Measures is an international, peer-reviewed, open access journal focusing on treatment outcomes specifically relevant to patients. All aspects of patient care are addressed within the journal and practitioners from all disciplines are invited to submit their work as well as healthcare researchers and patient support groups.
The journal is included in PubMed. The manuscript management system is completely online and includes a very quick and fair peer-review system. Visit http://www.dovepress.com/testimonials.php to read real quotes from published authors. 